\title{
Vygotsky: Um Referencial para Analisar a Aprendizagem e a Criatividade no Ensino da Física
}

\section{Vygotsky: A Benchmark for Analyzing Learning and Creativity in Physics Teaching}

\author{
Roberto Gonçalves Barbosa Brasil \\ Irinéa de Lourdes Batista ${ }^{\circledR}$ Brasil
}

Neste artigo, apresenta-se uma análise das respostas de estudantes da primeira série do Ensino Médio com relação aos conhecimentos da Física, particularmente referente às Leis de Newton. A análise foi realizada por meio da elaboração de unidades de registro prévias, fundamentadas em Vygotsky, que, entre outros aspectos incluiu a dimensão criativa. Esse viés é pouco frequente nas pesquisas em Ensino de Ciências. Dentre outras inferências, observa-se que classificar os diferentes níveis de aprendizagem sob o pensamento de Vygotsky implica em descrever um processo relacionado ao domínio gradual dos signos e significados científicos ligados aos diferentes níveis de consciência que se iniciam no saber espontâneo, passando pela fase quase-reprodutora e que culmina na reprodutora e reprodutora-criativa. Além dessa condição, é possível observar que a expressão criativa dos estudantes resulta da combinação de ao menos duas funções mentais, a imaginação e o pensamento em conceitos.

Palavras-chave: Vygotsky; Ensino e Aprendizagem de Física; Criatividade.

In this article, we present an analysis of the answers of students of the first grade of High School in relation to the knowledge of Physics, particularly referring to Newton's Laws. The analysis was performed through the elaboration of previous registration units, based on Vygotsky, which, among other aspects included the creative dimension. This bias is not frequent in research in Science Teaching. Among other inferences, it is observed that classifying the different levels of learning under Vygotsky's thinking implies describing a process related to the gradual mastery of the scientific signs and meanings linked to the different levels of consciousness that begin in spontaneous knowledge, passing through the almost-reproductive and culminating in the reproductive and reproductive-creative. Beyond this condition, it is possible to observe that the creative expression of the students' results from the combination of at least two mental functions, the imagination and the thought in concepts.

Keywords: Vygotsky; Teaching and Learning of Physics; Creativity. 


\section{Introdução}

A adoção do pensamento de Vygotsky e de sua teoria sócio-interacionista ou histórico-cultural nas pesquisas em Ensino de Física tem sido cada vez mais crescente. Os trabalhos que se dedicam ao tema têm contribuído principalmente para fomentar a reflexão e a crítica aos métodos e às práticas que ocorrem tradicionalmente em sala de aula (Pereira, \& Lima Jr., 2014; Rosa, \& Rosa, 2004), de modo especial com enfoque na dimensão interacional entre estudantes-estudantes e estudantes-docentes, inclusive no que se refere às atividades experimentais (Gaspar, \& Monteiro, 2005; Reis Jr., \& Silva, 2013).

Nesse panorama e com o objetivo de trazer novas contribuições às pesquisas em ensino de Física, no presente trabalho é apresentada uma análise das explicações dadas pelos estudantes da primeira série do Ensino Médio de uma escola pública para o movimento dos objetos. A análise foi realizada por meio de um conjunto de categorias e unidades previamente elaboradas e fundamentadas na teoria sociocultural, formulada por Vygotsky, em que se concebe a aprendizagem como resultado de um processo gradual de internalização dos códigos culturais, um processo que envolve a progressiva integração da criança no universo semiótico ou da significação. Segundo Pino (1993), "a entrada nesse universo supõe, portanto, o acesso ao circuito da comunicação, o que implica a mediação do outro" (p.19).

O aluno inserido no contexto escolar participa de um universo semântico e de comunicação em que passa por diferentes estágios de domínio, estágios estes que vão desde a reprodução até a reinvenção de signos e significados. Tal reinvenção ou ressignificação implica em criação, isto é, em criatividade, que é uma dimensão também considerada por Vygotsky, mas que é pouco reportada nas pesquisas em Ensino de Ciências (Barbosa, 2014), viés sobre o qual também se debruça ao longo deste trabalho.

\section{Vygotsky e o Ensino da Física}

$\mathrm{Na}$ concepção de Vygotsky, os sujeitos, ao entrarem em contato com outros membros da sociedade, internalizam hábitos e signos culturais que contribuem para o desenvolvimento do seu pensamento e de sua personalidade. Esse é um processo em que a escola tem um papel de destaque, pois além de ser responsável pela difusão do conhecimento científico elaborado e acumulado pela humanidade, o aprendizado escolar exerce influência decisiva no desenvolvimento das funções psicológicas superiores (atenção deliberada, memória lógica, abstração, capacidade para comparar e diferenciar), justamente na fase em que elas estão em amadurecimento (Rego, 1995). Essa prática permite que as crianças se conscientizem dos próprios processos mentais (processo metacognitivo). O conhecimento escolar é potencialmente promotor de zonas de desenvolvimento proximal, pois cria obstáculos de aprendizagem aos alunos individualmente, e estes, ao contar com a intervenção do professor ou de outros colegas, poderão mais tarde ultrapassá-los. 
No entanto, quando se considera o conhecimento físico, observa-se que a sua apropriação tem-se constituído, em sua maioria, em um obstáculo praticamente intransponível, principalmente quando se detém nos resultados escolares que envolvem essa disciplina. Ora, não é desconhecido o fato de que estudantes da educação básica e até do nível universitário têm apresentado altos níveis de incompreensão ou má compreensão dos conceitos físicos previamente ensinados (Finkelstein, 2005; Maloney, O’Kuma, Hieggelke, Curtis, \& Van Heuvelen, 2001; Leinonen, Asikainen \& Hirvone, 2012; Pritchard, Barrantes \& Belland, 2009).

De acordo com Vygotsky, tal situação significaria dizer que durante o ensino da Física não se tem gerado ou alargado a zona de desenvolvimento proximal dos alunos devido à limitação ou insuficiência nas explicações, o que poderia também indicar um baixo nível de desenvolvimento psicológico. Para autores, como, Robilotta e Babichak (1997), tal resultado se deve, entre outros fatores, à ênfase que se dá ao ensino e à aprendizagem de definições, por exemplo, “massa é isso, carga elétrica é aquilo ...” (p. 41), prática que é contumaz nas escolas brasileiras de nível médio e que requer dos estudantes altos níveis de abstração, atenção e consciência sobre as próprias percepções. Porém Vygotsky alerta que

A maior dificuldade é a aplicação de um conceito finalmente apreendido e formulado a um nível abstrato, a novas situações concretas que devem ser vistas nesses mesmos termos abstratos - um tipo de transferência que, em geral, só é dominado no final da adolescência. A transição do abstrato para o concreto mostra-se tão árdua para o jovem como a transição primitiva do concreto para o abstrato (Vygotsky, 1987, p.100).

Ademais, Robilotta e Babichak (1997) salientam que o problema do ensino que parte da definição verbal ou escrita de conceitos científicos é que ele sugere que o significado do conceito está no próprio conceito, que este não permite outras interpretações e que independe do contexto no qual é enunciado, o que não é verdade. O motivo pelo qual isso ocorre, apontam os autores, é o não (re)conhecimento pelos educadores de que o conhecimento físico é altamente estruturado e que apenas apresentar a definição de um conceito não leva à aprendizagem, uma vez que definir um conceito recai sobre outros conceitos tão desconhecidos e complexos para os estudantes como o que se quis definir. Considerando esse fato, Vygotsky (1987) afirmou que

o ensino direto de conceitos é impossível e infrutífero. Um professor que tenta fazer isso geralmente não obtém qualquer resultado, exceto o verbalismo vazio, uma repetição de palavras pela criança, semelhante a um papagaio, que simula um conhecimento dos conceitos, mas que na realidade oculta um vácuo (Vygotsky, 1987, p.104).

Um exemplo dessa situação é dado pelo físico norte-americano Andrea Disessa (1982) com relação ao conhecimento físico apreendido por uma de suas alunas.

No caso de Jane, nós vemos alguém que evidentemente não aprendeu muito até este nível. Sua Física ingênua inicialmente parece bloquear, mais que facilitar o uso daquilo que ela aprendeu na interpretação direta do fenômeno da interação e do movimento. Ela percebe e interpreta o mundo de um modo uniformizado, e incompatível com 
Newton. Um físico poderia dizer que ela não compreende Física, muito embora ela possa adicionar vetores e recitar $\mathrm{F}=\mathrm{m}$. a (Disessa, 1982, p.62).

O exemplo da aluna citada pode ser estendido ao modo como os docentes são formados, já que, de acordo com uma pesquisa realizada por Barbosa, Bellini e Silva (2012), com foco nas representações sociais docentes, observou-se que professores de Física do nível médio foram capazes de enunciar as leis de Newton, mas tiveram dificuldade em aplicá-las em situações físicas relativamente tradicionais e presentes em livros didáticos de Física. Dentre outras razões, sob o ponto de vista vygotskyano, isso ocorre porque um conceito não é aprendido por meio de um treinamento mecânico, tampouco pode ser diretamente transmitido pelo professor ao aluno.

\section{Relação entre Aprendizagem e Desenvolvimento}

Na concepção de Vygotsky (1987), a aprendizagem afeta o desenvolvimento, assim como o desenvolvimento interfere na aprendizagem, portanto, existe uma interdependência entre esses dois conceitos. Especificamente no âmbito escolar, Vygotsky (1987, p. 128) assinala que,

[...] os pré-requisitos psicológicos para o aprendizado de diferentes matérias escolares são, em grande parte, os mesmos; o aprendizado de uma matéria influencia o desenvolvimento das funções superiores para além doslimites dessa matéria; as principais funções psíquicas envolvidas no estudo de várias matérias são interdependentes - suas bases comuns são a consciência e o domínio deliberado, as principais contribuições dos anos escolares.

Tais constatações encerram a ideia de que os conhecimentos difundidos na escola, apesar de terem raízes teóricas, experimentais, filosóficas e históricas distintas, são "transmitidos" por meio de um elemento cultural comum, a linguagem falada e escrita, cujas características abrangem a abstração, a representação e a conceituação.

\section{A Zona de Desenvolvimento Proximal}

A ZDP (Zona de Desenvolvimento Proximal) é o estágio de desenvolvimento psicológico associado à aprendizagem e que é identificado por meio da expressão da capacidade potencial da criança em realizar uma tarefa e/ou resolver determinado problema com o auxílio de alguém. Especificamente, a ZDP

é a distância entre o atual nível de desenvolvimento determinado pela capacidade de resolver um problema individualmente e o nível de desenvolvimento potencial determinado por meio da capacidade de resolver um problema sob a orientação de um adulto ou em colaboração com um colega mais capaz (Vygotsky, 1987, p. 86).

Para Vygotsky, o bom aprendizado ${ }^{1}$ é aquele que se adianta ao desenvolvimento,

$1 \mathrm{O}$ termo aprendizado deve ser entendido em um sentido mais amplo do que aquele que é empregado na língua portuguesa. Quando Vygotsky fala em aprendizado (obuchenie, em russo), ele se refere tanto ao processo de ensino quanto ao de aprendizagem, porque ele acredita que é impossível tratar desses dois aspectos de forma independente (Rego, 1995, p. 72). 
ou seja, que se volta para aquelas funções mentais que estão em fase de amadurecimento, e que, portanto, exigem a participação ou a interferência de alguém para o seu desenvolvimento. Segundo Oliveira (2010, p. 65),

A implicação dessa concepção de Vygotsky para o ensino escolar é imediata. Se o aprendizado impulsiona o desenvolvimento, então a escola tem um papel essencial na construção do ser psicológico adulto dos indivíduos que vivem em sociedades escolarizadas. Mas o desempenho desse papel só se dará adequadamente quando, conhecendo o nível de desenvolvimento dos alunos, a escola dirigir o ensino não para etapas intelectuais já alcançadas, mas para estágios de desenvolvimento ainda não incorporados pelos alunos, funcionando realmente como um motor de novas conquistas psicológicas. Para a criança que frequenta a escola, o aprendizado escolar é elemento central no seu desenvolvimento.

Nessa perspectiva, Palangana (1998) salienta que a compreensão do conceito de zona de desenvolvimento proximal encaminha os estudos psicológicos para uma reavaliação do papel da imitação na aprendizagem, pois Vygotsky observou que as crianças podem imitar ações que vão muito além de suas capacidades reais ou efetivas, o que cria zonas de desenvolvimento potencial.

\section{Vygotsky e a Consciência}

Vygotsky (1987) utiliza a palavra consciência para indicar a percepção da atividade da mente - a consciência de estar consciente -, processo em que os indivíduos selecionam atos de pensamentos de sua atividade mental total e sobre os quais centram a sua atenção. No contexto escolar,

os conceitos científicos com o seu sistema hierárquico de inter-relações, parecem constituir o meio no qual a consciência e o domínio se desenvolvem, sendo mais tarde transferidos a outros conceitos e a outras áreas do pensamento (Vygotsky, 1987, p. 115).

Esse processo depende do desenvolvimento mental do sujeito, de modo particular, da capacidade de formar conceitos, isto é, significar, de maneira consciente e deliberada, um objeto em meio a uma miríade de significados, processo que ocorre por meio de uma passagem de um nível de percepção para outro, o que permite criar novas possibilidades de significação e/ou representação.

\section{Vygotsky e a Criatividade}

Vygotsky realizou estudos a respeito da criatividade vinculada à ideia de imaginação e do pensamento por conceitos em crianças e adolescentes. Segundo Moran e Jonh-Steiner (2003, p. 981),

Vygotsky elaborou dois artigos e uma palestra com foco no desenvolvimento da habilidade criativa: Imaginação e criatividade na infância em 1930, Imaginação e criatividade na adolescência em 1931 e Imaginação e seu desenvolvimento na infância em 1932. Smolucha (1992) sintetizou as ideias de tais trabalhos afirmando que a imaginação criativa consiste num objetivo orientado, um sistema psicológico 
mediado culturalmente que emerge da internalização da brincadeira infantil e do interrelacionamento funcional da imaginação e do pensamento com conceitos.

Em seus próprios termos, Vygotsky (1994) salienta que a imaginação e a criatividade estão relacionadas à reelaboração e combinação de diversos elementos da experiência, processo que ocorre com a pré-condição de que haja um nível de liberdade interior de pensamento, ação e cognição, cujo domínio está ao alcance apenas do sujeito que dominar o pensamento conceitual. No entanto, o domínio do pensamento conceitual só é atingido durante a fase final da adolescência, estágio em que ocorre a transição de uma imaginação infantil passiva e imitativa para uma imaginação ativa e criativa. Durante essa fase, o adolescente tem plena consciência de sua subjetividade bem como do fato de que o seu pensamento difere de sua imaginação.

Para Vygotsky (1994), o pensamento imaginativo adolescente tem duas vias ou canais. O primeiro está ligado à satisfação emocional que se relaciona a todos os aspectos da vida do adolescente, seus modos, carências e sentimentos. Durante esse estágio, o adolescente tem a necessidade de criar um mundo fantasioso e desejável, em comparação a uma realidade concreta e indesejada. A imaginação, para ele, é um meio de expressar a sua vida emocional interior e oculta, um meio de se libertar das condições externas e cotidianas que o afligem.

$\mathrm{Na}$ outra via, paralela à imaginação emocional, encontra-se a criatividade objetiva que está relacionada à imaginação, à criação de algum tipo de estrutura, nova e concreta, uma nova imagem da realidade, uma configuração criativa de alguma ideia (Vygotsky, 1994). E é graças a essa capacidade que a humanidade é capaz de criar obras literárias, científicas e técnicas.

Durante esse estágio de desenvolvimento mental, ocorre uma reaproximação entre a imaginação e o pensamento por conceitos que levam a um enriquecimento da capacidade criativa humana. E é justamente durante esse estágio que, pela primeira vez, o adolescente vislumbra a possibilidade de descobrir o curso que a sua vida está tomando, o que se torna possível devido ao fato de que, ao utilizar-se de sua imaginação, ele antecipa o seu futuro e, consequentemente, aproxima-se de sua construção e realização criativa.

Logo, para Vygotsky (1994), a imaginação é uma manifestação da atividade criativa humana que, durante a adolescência, vincula-se à capacidade de pensar conceitualmente, esta, por sua vez, leva à reelaboração criativa do mundo. Ademais, a expressão criativa, que se efetiva por meio da imaginação, serve como uma via de alívio emocional, tanto no adolescente quanto no adulto.

A atividade criativa da imaginação depende diretamente da riqueza e da variedade das experiências prévias das pessoas porque esta experiência fornece o material a partir da qual os produtos da imaginação são construídos. Quanto mais rica a experiência de uma pessoa mais rico é o material que a imaginação poderá acessar (Vygotsky, 2004, p.14).

Tais observações desconstroem dois mitos: o de que a imaginação criativa seja privilégio de uns poucos (inventores, gênios, etc.) e o de que ela seja mais desenvolvida 
na criança do que no adulto.

\section{Explicação científica na escola: reprodução ou reprodução- criativa}

$\mathrm{Na}$ concepção de Vygotsky, qualquer atividade humana que dá origem a algo novo se refere a um ato criativo, independentemente do fato de que se o que foi criado é um objeto físico ou um constructo mental ou emocional que vive dentro do sujeito que o criou e é reconhecido somente por ele (Vygotsky, 1987). Esse algo que se pode criar ou recriar depende do contexto sociocultural bem como dos materiais e instrumentos disponíveis, os quais, por sua vez, condicionam a elaboração de um produto novo ou criativo.

Nesse sentido, no âmbito escolar e disciplinar, a criatividade do estudante quando requerida também depende do modo de ver e pensar da Ciência bem como de sua linguagem. No campo da Física, por exemplo, a criatividade, quando expressa pelo estudante, deve estar vinculada aos fundamentos dessa área de conhecimento, por isso se pode chamá-la de criatividade-reprodutora. Ora, há que se levar em consideração que explicar uma situação sob os moldes da Física sem fazer uso de seus signos e significados já não é mais explicá-la fisicamente. Segundo Pino (1993), a criatividade-reprodutora ou reprodução-criação

consiste no processo de assimilação dos códigos culturais, signos e significados pelos sujeitos e que são reelaborados, ressignificados e aplicados a outros contextos. Porém, em muitos casos esse processo de recriação não ocorre, quer dizer, o sujeito apenas repete as ideias e o pensamento de outros sujeitos o que o leva a alienar-se de si, cujo um não-eu fala pelo eu, ou melhor, trata-se de um processo de participação fusional do "eu" no "outro" de tipo alienante, pois identificando-se com o significante-referente (objeto a que se refere) o "eu" perde-se no "outro" ignorando-se a si mesmo (Pino, 1993, p.19).

Nessa perspectiva, as repostas dos estudantes podem ser classificadas de dois modos, reprodutora ou reprodutora-criativa. Na primeira, os alunos expressam as ideias e a linguagem do conhecimento científico ao qual eles se referem, mais ou menos de maneira estrita. Nesse tipo de resposta, destaca-se a voz ${ }^{2}$ do livro didático, é o professor, quer dizer, a linguagem-pensamento adotada pela comunidade acadêmica científica. Trata-se especificamente de uma das funções da imitação que implica, segundo Pino (1993), "em uma dupla operação semiótica, em que a reprodução do modelo se constitui em significante desse modelo, o qual, por sua vez, refere-se à pessoa imitada" (p.19). Nesse caso, ocorre um tipo de alienação de si mesmo pelo próprio sujeito, processo em que a voz do "eu" expressa o pensamento do "outro" (Wertsch, 1985).

Na segunda, a expressão reprodutora-criativa, as vozes dos estudantes aparecem,

2 O termo voz é derivado do trabalho do pesquisador literário e filósofo soviético Mikail Bakhtin (1981) para o qual a voz está relacionada "a fala da personalidade" e "a fala da consciência". Segundo Wertsch (1993) a voz da personalidade envolve alguém que toma uma certa perspectiva ou pertence a um determinado grupo cultural e social. "Ambos Vygotsky e Bakhtin acreditavam que as práticas de comunicação humana dão origem ao funcionamento mental nos indivíduos" (Wertsch, 1993, p. 13). 
ou seja, é o "eu" falando por si. Entretanto o "eu" está vinculado a um "não-eu", ou seja, ao pensamento-linguagem da Física que deve ser expresso quando solicitado. Assim, essa expressão que reproduz, mas que também cria, resulta da apreensão significativa dos conceitos e ideias da Física, contexto em que o estudante é capaz de aplicar tais conhecimentos a outros contextos ou situações e/ou quando utiliza a própria linguagem para explicar um aspecto físico presente em determinado objeto de estudo. Essa dimensão é criativa porque no nível intrapsicológico ocorre um processo em que o estudante se distancia da realidade concreta por meio da abstração proporcionada pelo pensamento em conceitos, ao mesmo tempo em que a imaginação combina diversos elementos da experiência concreta de uma forma criativa, o que resulta em novas estruturas. Para Vygotsky (1994), "o movimento de uma forma concreta por meio do abstrato, a construção de uma nova forma de uma imagem concreta, é a via pela qual se descreve a imaginação na adolescência" (p. 283). Essa capacidade imaginativa somada ao pensamento abstrato conceitual pode levar à reconstrução, reconstituição e ressignificação dos objetos e signos de uma forma criativa pelos sujeitos.

\section{Objeto de pesquisa}

Para empreender esta pesquisa, debruçou-se sobre duas questões: Qual é a função da consciência, da imaginação e do pensamento em conceitos no processo de internalização dos conceitos e dos princípios físicos? e Qual é a relação da aprendizagem dos conhecimentos físicos com a ZDP?

\section{Contexto de Aplicação da pesquisa}

Esta pesquisa foi realizada com estudantes de duas turmas da $1^{\text {a }}$ série do período noturno do Ensino Médio, em uma escola da rede pública estadual, localizada ao norte do Estado do Paraná. Em uma turma havia 25 alunos com idades entre 15 e 18 anos e, na outra, 22 alunos com idades entre 14 e 19 anos. Após a assinatura dos termos de consentimento pelos estudantes ou por seus responsáveis, as atividades foram desenvolvidas, individualmente e em grupos de 2 (dois), 3 (três) e 4 (quatro) alunos, totalizando 27 equipes. Os grupos foram classificados em Grupo 1A, Grupo 2A, ... e Grupo 1B, Grupo 2B... .

Para este estudo especificamente, desenvolveu-se com as duas turmas uma sequência didática com base nos seguintes referenciais: pedagogia freireana, abordagem metodológica de Angotti e Delizoicov, abordagem CTS, e nos estudos em criatividade (Alencar, 2004). A sequência constituiu-se de 5 momentos pedagógicos cujos objetivos são apresentados a seguir.

(1) Os estudantes-sujeito e o mundo-escola, momento em que se buscou promover a reflexão dos estudantes sobre si mesmos e sobre $\mathrm{o}$ ato de estudar bem como problematizar a presença, as práticas e a participação dos estudantes no ambiente escolar.

(2) Os estudantes e as relações CTS, em que se fomentou a reflexão dos estudantes a respeito do seu relacionamento com os objetos tecnocientíficos com os quais eles 
interagem em seu cotidiano. Além disso, teve como propósito aproximar a cultura científica da cultura dos estudantes.

(3) Como a Física explica o mundo: esse momento foi dedicado à exposição do modo como a física explica-descreve o mundo.

(4) A explicação da Física para o movimento da bicicleta teve como objetivo apresentar aspectos simbólicos (setas), representativos (esquemas) e conceituais da Física (forças, força motriz, forças de contato, e as leis de Newton), utilizando como exemplo o movimento de uma bicicleta.

(5) Atividade síntese ou aplicação do conhecimento, por sua vez, visou a oportunizar uma atuação autônoma pelos estudantes, promover um momento para que os eles pudessem aplicar seus conhecimentos e fomentar a expressão criativa.

A aplicação da sequência didática durou aproximadamente 2 (dois) meses. E a coleta de dados foi realizada pelo professor pesquisador-participante e um dos autores desse trabalho. Os dados analisados se referem exclusivamente às respostas escritas pelos estudantes e que foram transcritas integralmente neste artigo.

\section{Abordagem metodológica}

A análise se concentrou nas respostas registradas pelos estudantes, relativas à atividade contida no quinto momento pedagógico da sequência didática. Essa atividade foi escolhida devido ao fato de ser uma questão aberta e que dá liberdade para que os estudantes escolham um objeto, ao mesmo tempo em que possibilita que os conhecimentos apreendidos sejam reproduzidos ou ressignificados. Nesse sentido, propôs-se:

Escolha um objeto: meio de locomoção, pessoa, animal ou inseto que se mova e faça uma análise física utilizando as três leis de Newton para o movimento.

Para o tratamento dos dados, utilizaram-se os instrumentos de análise de conteúdo de Bardin (1977), devido à necessidade de desvelar as relações que se estabelecem além das falas propriamente ditas e por contribuir no enriquecimento da leitura via compreensão das significações. Ademais, a análise temática categorial permitiu delimitar as hipóteses e os pressupostos, a partir das quais, ao considerar o pensamento de Vygotsky, elaboraramse unidades de registro (UR). A unidade temática ou de significação foi definida com base no saber procedimental, na explicação-descrição dos fenômenos bem como no saber conceitual referente às leis de Newton. Unidades que são assim apresentadas:

Unidade temática ou de significação

Explicação-descrição adotada pelos estudantes para descrever o movimento dos objetos segundo as leis de Newton. 
Unidades de Registro

UR.1) Explicação espontânea ou não-reprodutora: apresenta uma resposta em que não se utilizam conceitos científicos ou ideias científicas. Trata-se de um estágio nãoconsciente, em que o estudante não dirige sua atenção para os seus atos de pensamento, mas para o objeto a que se refere.

UR.2) Explicação quase-reprodutora: apresenta uma explicação em que se utilizam conceitos físicos, jargão, mas se concentra em outros aspectos que a Física geralmente despreza ao explicar o movimento dos corpos. Durante esse estágio, o estudante está na zona de transição de um pensamento inconsciente para um consciente.

UR.3) Explicação reprodutora ou imitação alienante: apresenta uma explicação em que se utilizam conceitos físicos, jargão e se concentra em aspectos considerados pela Física para explicar o movimento dos corpos. Esse é um estágio em que o estudante tem consciência dos seus próprios processos mentais, porém se remete ao pensamento e à linguagem do outro.

UR.4) Explicação reprodutora-criativa ou imitação não-alienante: apresenta uma explicação que se utilizam os conceitos e ideias da Física por meio de sua própria linguagem. No decorrer desse estágio, o estudante tem consciência dos seus próprios processos mentais, mas vai além da fala do outro, isto é, ele se volta para o "eu", o que o leva à ressignificação dos conceitos físicos.

\section{Dados e discussão}

Os dados apresentados a seguir são analisados e discutidos em quatro perspectivas: a ideia de internalização, a ZDP (Zona de Desenvolvimento Proximal), a consciência e a criatividade.

\section{A internalização dos signos e significados da Física}

$\mathrm{Na}$ perspectiva de Vygotsky, a aprendizagem está relacionada ao processo de internalização. Embora esse processo não se restrinja à aprendizagem considera-se que a aprendizagem advém do mesmo, segundo o qual o sujeito domina de maneira gradual os códigos culturais ( signos e significados) que lhe são externos. E como a aprendizagem é aqui entendida como um processo, a internalização pode ser total ou parcial.

Nesta pesquisa, considerando-se a totalidade dos dados reunidos e classificados em ambas as turmas, observa-se um número significativo de respostas que mostram um domínio parcial das noções a respeito das leis de Newton. Tais respostas, em sua maioria, caracterizam-se pela falta ou adição de informações bem como pela consideração de interações que a Física despreza. Por exemplo, nas respostas apresentadas a seguir os estudantes parecem compreender a terceira lei de Newton, porém consideram a interação motorista-acelerador, o que se diferencia da Física que considera a interação entre pneu-solo.

G9A. [...] O carro também obedece à lei de Newton, a lei da ação e reação, quer dizer, a 
ação do motorista sobre o acelerador faz o carro andar.

G4A. Você acelera a moto, e conforme você acelera, o motor faz uma força e puxa as rodas para fazer um movimento para frente.

Embora essas respostas estejam incorretas do ponto de vista da Física, na perspectiva da teoria de Vygotsky elas se classificam como quase-reprodutoras, pois explicitam a ideia de causa e efeito, que, nesse aspecto, coincide com a noção Física. $\mathrm{O}$ mesmo ocorre com os trechos a seguir, que quase imitam a lei da Inércia, porque não mencionam o aspecto geométrico desse princípio, que é a retilinearidade do movimento, bem como o caráter constante da velocidade.

G6A. $1^{\text {a }}$ Lei - No caso do ônibus, o estado de inércia estará presente quando o conjunto ônibus+motorista estiver em repouso ou em movimento com uma velocidade sempre igual. Nesse caso, pode-se afirmar que o que move o ônibus é a inercia do conjunto ônibus+motorista.

G4B. A primeira lei de Newton que diz que todo corpo permanece em repouso ou em movimento em linha reta, desde que nenhuma força aja sobre ele.

Logo, o que esses dois exemplos têm em comum não é a expressão de um conhecimento errôneo, mas sim, a expressão de um pensamento que está em certo estágio de desenvolvimento dentro do processo de aprendizagem da Física. Ora, ter consciência dessa condição evita cair no dualismo fatalista do certo ou errado que marca o sistema de avaliação, e que exclui aqueles estudantes que não reproduzem o conhecimento científico de maneira estrita.

Nessa perspectiva, deve-se pensar o ensino e a aprendizagem de maneira processual. Processo este que, vinculado ao desenvolvimento intelectual dos estudantes no âmbito escolar, volta-se para a formação de conceitos, um processo marcado por três estágios: o primeiro, o de amontoados sincréticos; o segundo, o de pensamento por complexos, e o terceiro, pensamento por conceitos.

Nesta pesquisa, em particular, os dados sugerem que o pensamento relativo ao conhecimento físico expresso nas respostas dadas pelos estudantes se aproxima do que Vygotsky chamou de pensamento por complexos, o qual se situa em um nível anterior ao nível de desenvolvimento da formação de conceitos. O pensamento por complexos se caracteriza pela ligação dos sujeitos a objetos concretos e factuais, e não a entidades abstratas e lógicas ${ }^{3}$ (Vygotsky, 1987). Por exemplo, nos trechos transcritos abaixo os estudantes relacionam o movimento do ônibus ao de um automóvel com o ato de acionar a chave, pegar no volante ou pisar no acelerador,

G1A.O movimento do ônibus acontece a partir do momento em que ele liga o ônibus e acelera.

3 Aqui, não se entende como uma falta de lógica, mas da ausência de um núcleo estável de significação definido, tal como ocorre com o pensamento científico. 
G2A. A ação do piloto sobre o acelerador e o volante fazem com que a hélice gire e o avião voe.

G3A. A velocidade do carro ocorre devido ao uso da gasolina, que se ejeta no pistão, gerando uma força que faz o movimento do carro. Isso faz o carro sair do repouso para a movimentação.

G9B. A força é gerada pelo motor, que é movido a combustível e com o movimento do pé no acelerador, o veículo se move. O carro também obedece à lei de Newton, a lei da ação e reação, quer dizer, a ação do motorista sobre o acelerador faz o carro andar.

Tais respostas se baseiam em um objeto observável e não em um ente abstrato, como o conceito de força. Ademais, essa forma de pensamento, ao contrário do pensamento conceitual ou científico, permite inúmeras interpretações. Assim, "enquanto um conceito agrupa os objetos de acordo com um atributo, as ligações que unem os elementos em um complexo ao todo, e entre si, podem ser tão diversas quanto os contatos e as relações que de fato existem entre os elementos" (Vygotsky, 1987, p.77). No caso da Física, a explicação para o movimento de um corpo se funda em um ente abstrato, o conceito de força, que prescinde da presença do sujeito.

\section{A ZDP (Zona de desenvolvimento proximal)}

A ZDP define as "funções ainda não amadurecidas, mas que encontram-se em processo de amadurecimento, as funções que amadurecerão amanhã, estão hoje em estado embrionário" (Prestes, 2010, p.173). Para Vygotsky (1994), a aprendizagem se relaciona dialeticamente com o desenvolvimento. Ele, sobretudo, afirma que de modo geral a aprendizagem precede o desenvolvimento, quer dizer, aprender pode levar ao desenvolvimento intelectual ou mental dos sujeitos.

$\mathrm{Na}$ escola, em particular, o conhecimento é ensinado por meio de conceitos, logo é na linguagem e por meio da linguagem que os estudantes conhecem o mundo, que é o elemento comum entre todas as disciplinas escolares. Entretanto conhecer o mundo por meio da linguagem traz muitas dificuldades para os estudantes, que devem apreender objetos isolados e abstratos que pertencem a um sistema hierarquizado de ideias predefinidas.

No âmbito do ensino da Física, aprender implica em dominar conceitos, ideias e formas de representar e simbolizar. Esses parâmetros permitiram observar se tais capacidades pertenciam à zona de desenvolvimento potencial dos estudantes. Uma das principais conclusões inferidas foi que as práticas que buscam representar, descrever e explicar uma situação por meio de regras, conceitos e leis da Física, no estrito sentido do termo, não atuam na ZDP da maioria dos estudantes analisados. Tal conclusão encontra fundamento em inúmeras pesquisas que tratam da má compreensão das ideias da física (Ebenezer, \& Fraser, 2002; Finkelstein, 2005; Leinonen, Asikainen, \& Hirvone, 2012; Maloney et al., 2001).

Por outro lado, considerando o pensamento vygostskyano de que a educação 
deve voltar-se para aquelas funções mentais que estão em fase de amadurecimento, identificam-se as seguintes possibilidades intelectuais externalizadas pelos estudantes de acordo com a tarefa realizada:

a) aplicar o conceito de força: os estudantes parecem ter compreendido a ideia de força como geradora de movimento, porém consideram a interação do sujeito com o volante ou o acelerador para explicar a razão do movimento.

b) explicar processualmente ou descritivamente uma situação: embora tenham considerado aspectos desprezados pela Física, os estudantes deram uma explicação procedimental ou descritiva para o movimento de um móvel.

c) reproduzir ou imitar princípios físicos por meio da utilização de um material de apoio: uma pequena parcela dos estudantes foi capaz de imitar a terminologia e os enunciados presentes no material didático disponibilizado.

d) aplicar as leis Físicas de forma reprodutora e criativamente em novas situações: uma pequena parcela dos estudantes (somente 2 grupos da turma A) conseguiu utilizar a própria linguagem para explicar fisicamente uma situação.

Tais possibilidades foram classificadas como pertencentes à zona de desenvolvimento proximal dos estudantes analisados, porque foram expressas durante a resolução da atividade proposta com o auxílio dos colegas do grupo e do professor.

\section{O saber e a consciência}

Segundo Vygotsky (1997), a consciência e o controle deliberado caracterizam as funções intelectuais superiores. São funções sobre as quais as crianças passam a ter um domínio maior durante a idade escolar, pois o aprendizado conceitual abstrato e de relações hierarquizadas as leva a tomar consciência dos próprios processos mentais. Nesse sentido, foi possível evidenciar por meio dos dados coletados três níveis ou estágios de consciência dos estudantes: o não consciente, o estágio intermediário de consciência (processo de tomada de consciência) e o pensamento consciente.

O primeiro, o pensamento não consciente, é aquele em que os estudantes utilizam palavras e ideias provenientes do seu entorno social, ideias essas que, sobretudo, caracterizam-se pela ausência de entes abstratos e de um sistema conceitual que possa mediar a relação com o objeto. Isso ocorre porque, ao operar com conceitos espontâneos, as crianças não estão conscientes deles, pois a sua atenção está sempre centrada no objeto ao qual se referem, nunca no próprio ato de pensamento (Vygotsky, 1987). É o que se pode observar nos trechos citados a seguir:

G5A. O motor tem a gasolina que manda força para o motor que é queimada e o carro se movimenta. 
G8A. A ação do piloto com o acelerador e o volante faz com que a hélice gire, o avião sai do solo.

Conforme se pode observar, são respostas que não lidam com conceitos, mas quase que exclusivamente com objetos perceptuais. Por outro lado, metade das respostas evidenciou um processo de tomada de consciência pelos estudantes, particularmente, um estágio de transição em que os alunos mesclavam conhecimentos científicos com conhecimentos espontâneos. Vejam-se os exemplos,

G4B. A primeira lei de Newton que diz que todo corpo permanece em repouso ou em movimento em linha reta, desde que nenhuma força aja sobre ele.

G11B. Ação = quando a hélice puxa a água

Reação= é quando empurra o barco

Inércia = é quando o navio está em repouso.

Nos trechos acima apresentados, constata-se que embora os alunos utilizem os princípios e conceitos físicos, eles falham em informações que os levariam a sua estrita reprodução ou imitação, que então seria caracterizada como a expressão de um pensamento consciente.

O pensamento consciente é representado por duas situações, quando os estudantes reproduzem ou imitam os conceitos e princípios físicos ou quando eles são capazes de reproduzi-los criativamente. Nessa amostra, apenas dois grupos expressaram em suas respostas uma reprodução criativa do conhecimento físico, em contraste com 6 grupos que imitaram ou reproduziram. Embora os dois grupos tenham sido classificados como sujeitos que se apoiaram em um pensamento consciente, os estudantes que aplicaram o conhecimento físico a um novo objeto ou utilizaram outra linguagem estão em um nível superior ao daqueles que somente imitaram. Esse resultado indica que o estudante que consegue reproduzir-criar fisicamente uma situação específica também será capaz de ver outro fenômeno em uma perspectiva que transcenda o saber espontâneo que está vinculado a um estado não consciente.

\section{A criatividade dos estudantes}

No âmbito escolar e disciplinar, a criatividade do estudante depende do modo de ver e pensar da Física bem como de sua linguagem. Portanto, dentro do campo da Física, a criatividade se classifica como reprodutora, quer dizer que se cria a partir dos fundamentos dessa área de conhecimento. Segundo Pino (1993), “o processo de reprodução-criação, consiste no processo de assimilação dos códigos culturais, signos e significados pelos sujeitos e que são reelaborados, ressignificados e aplicados a outros contextos" (p. 19). A capacidade de reconstituir um objeto ou signo via imaginação e pensamento por conceitos expressa a criatividade dos estudantes, processo que se dá por meio de pelo menos duas operações semióticas, a internalização dos códigos culturais e 
a ressignificação do já significado culturalmente.

Nessa pesquisa, constata-se, por um lado, que a maioria significativa dos estudantes não reproduziu criativamente os conceitos e princípios físicos durante a atividade proposta. Esse resultado reforça que os conceitos e ideias da física são de difícil apreensão e aqueles que a assimilam de maneira parcial ou total estão condicionados a seguir prescrições e a reproduzir conhecimentos, ao invés de criá-los ou recriá-los, conforme já destacou Alencar (2004).

Por outro lado, apenas duas respostas foram classificadas como pertencentes à unidade de registro - reproduzir-criar, porque os alunos que as formularam utilizaram uma terminologia do seu cotidiano para explicar, por meio das leis de Newton, o movimento no skate e na carroça, conforme se pode observar a seguir.

$1^{\circ}$ Lei: quando corpo permanece em cima do shape, corpo reto se equilibrando com os braços.

$2^{\circ}$ Lei: a força é responsável por gerar movimento, é o pé que vai remando no chão.

$3^{\circ}$ Lei: toda ação tem uma reação isso ocorre no skate quando nos batemos o pé no chão e faz com que o skate tenha movimento.

No caso do skate, "remar" significa produzir movimento por meio de uma força. Já no caso da carroça, o "estímulo" se refere à alteração da direção do movimento por meio da ação de uma força, conforme demonstra o exemplo abaixo.

$1^{\text {a }}$ Lei de Newton: quando a carroça está parada, não há movimento se o animal não introduzir força sobre ela.

$2^{\text {a }}$ Lei de Newton: quando o condutor estimula o animal a traçar outro caminho ou outra direção.

$3^{\text {a }}$ Lei de Newton: quando o animal se movimenta, ele puxa a carroça automaticamente.

Tais exemplos expressam o resultado de um complexo processo mental que envolve a imaginação e a capacidade de pensar conceitualmente. Segundo Vygotsky (1994),

a imaginação é uma atividade criativa transformadora que se move de uma de forma de concretude para outra, mas o mero movimento de uma dada forma concreta para uma forma recém-criada e a própria viabilidade de uma construção criativa somente é possível com a ajuda da abstração. (p.282).

Nesses exemplos, levando em consideração a situação concreta imaginada, "andar de skate e de carroça", o conceito de força pôde ser substituído por remar e estimular, graças à abstração propiciada pelo pensamento em conceitos. E é a essa ressignificação que se denomina criativa, em termos de processo da recombinação de elementos da experiência bem como do produto que ela gera. Tal situação vai ao encontro da ideia de que "o cérebro não é apenas um órgão que armazena [...] nossas experiências prévias, 
ele é também um órgão que combina criativamente e restaura elementos de experiências passadas [...] para gerar novas proposições e novos comportamentos" (Vygotsky, 2004, p. 9).

\section{Considerações finais}

Adotar o pensamento de Vygotsky para compreender os processos psíquicos envolvidos na aprendizagem dos conhecimentos científicos implica em considerar as diferentes funções do pensamento, como, a consciência, a imaginação e o pensar em conceitos. Esses elementos ajudam a caracterizar as diferentes fases da aprendizagem e do desenvolvimento dos estudantes com relação à capacidade de significar ou ressignificar conceitos e princípios físicos, caracterizando-se como um processo que envolve o domínio gradual dos signos e significados científicos associados a níveis cada vez maiores de consciência. Entretanto, mais que prover uma análise da aprendizagem dos estudantes, essas três funções mentais levam a pensar os sujeitos na perspectiva do desenvolvimento, da capacidade de imaginar, de pensar em conceitos e de aplicá-los a outros objetos ou contextos. Depreende-se, então, que a ressignificação do conceito de força, por meio das palavras "remar" e "estimular", representa um nível de pensamento superior, em que os estudantes, de maneira consciente, aplicam os conhecimentos internalizados a outro objeto, ou seja, passam deliberadamente do sistema conceitual espontâneo para o científico.

Tais ideias permitem questionar o ensino direto de conceitos que tradicionalmente vem sendo realizado nas escolas bem como a concepção de aprendizagem como um processo de acumulação de palavras e frases vazias de sentido na memória dos estudantes. Como destacou Vygotsky (1987) e Robilotta e Babichak (1997), o ensino direto de conceitos aos estudantes é impossível e infrutífero, uma vez que a formação de um conceito está relacionada ao desenvolvimento de muitas funções intelectuais, como, a abstração, a atenção deliberada, a memória lógica e a capacidade de comparar e diferenciar. "Um professor que tenta fazer isso tem como resultado um verbalismo oco, uma repetição de palavras pela criança semelhante à de um papagaio" (Vygotsky, 1987, p. 104).

Esse quadro suscita questões para futuras pesquisas, como: Qual conhecimento físico leva a um ou outro nível de desenvolvimento mental dos estudantes? Como romper com o ensino direto de conceitos nas aulas de física? Qual abordagem metodológica é mais adequada para promover um ensino de física voltado ao desenvolvimento da capacidade de imaginar e de pensar em conceitos? Essas são algumas questões que precisam ser respondidas, aliadas a uma maior compreensão dos aspectos volitivos e afetivos que estão envolvidos na internalização dos conceitos científicos, o que, para Vygotsky, constitui-se em uma dimensão fundamental para a compreensão plena do pensamento de outrem. 


\section{Agradecimentos}

Os autores agradecem à Capes.

\section{Referências}

Alencar, E. S. de. (2004). Como desenvolver o potencial criador: um guia para a liberação da criatividade em sala de aula. Petrópolis: Vozes.

Barbosa, R. G. (2014). Educação científica e tecnológica para a participação: Paulo Freire e a criatividade. Tese (Doutorado),Programa de Pós-Graduação em Ensino de Ciências e Educação Matemática da Universidade Estadual de Londrina, Londrina.

Barbosa, R. G., Bellini, M., \& Silva, A. M. T. B. (2012). A teoria das representacões sociais da física newtoniana: um estudo com professores do Ensino Médio. Semina: Ciências Sociais e Humanas, Londrina, 33(1), 3-16.

Bardin, L. (1977). Análise de conteúdo. Tradução de Luís A. Reto e Augusto Pinheiro. São Paulo: Martins Fontes.

Disessa, A. A. (1982). Unlearning Aristotelian Physics: a study of knowledge-based learning. Cognitive Science, 6(1), 37-75.

Finkelstein, N. (2005). Learning physics in context: a study of student learning about electricity and magnetism. International Journal of Science Education, 27, 1187-1210.

Gaspar A., \& Monteiro, I. C. de C. (2005). Atividades experimentais de demonstrações em sala de aula: uma análise segundo o referencial da Teoria de Vygotsky. Investigações em Ensino de Ciências, 10(2), 227-254.

Leinonen, R., Asikainen, M. A., \& Hirvone, P. E. (2012). University Students Explaining Adiabatic Compression of an Ideal Gas - A New Phenomenon in Introductory Thermal Physics. Research in Science Education, Abington, 42(6), 1165-1182.

Maloney D. P., O’Kuma, T. L., Hieggelke, Curtis, J., Van Heuvelen, A. (2001). Surveying students' conceptual knowledge of electricity and magnetism. Physics Education Research, American Journal Physics Supplement, 69(7), 12-23.

Moran, S., \& V. John-Steiner. (2003). Creativity in the Making: Vygotsky's Contemporary Contribution to the Dialectic of Creativity \& Development. In Creativity and Development, counterpoints: Cognition, Memory and Language. New York: Oxford University Press.

Pereira, A. P., \& Lima Jr, P. (2014). Implicações da perspectiva de Wertsch para a interpretação da teoria de Vygotsky no ensino de Física. Caderno Brasileiro de Ensino de Física, 31(3), 518-535.

Pino, A. L. B. (1993). Processos de significação e constituição do sujeito. Temas em Psicologia, (1), 17-24. 
Prestes, Z. R. (2010). Quando não é quase a mesma coisa: Análise de traduções de Lev Semionovitch Vigotski no Brasil, Repercussões no campo educacional. (Tese de Doutorado em Educação), Faculdade de Educação, Universidade de Brasília, Brasília.

Pritchard, D. E., Barrantes, A., \& Belland, B. R. (2009). What Else (Besides the Syllabus) Should Students Learn in Introductory Physics? MIT Facult Newsletter, 22(2), 9-11.

Rego, T. C. (1995). Vygotsky: uma perspectiva histórico-cultural da educação. 2. ed. Petrópolis: Vozes.

Reis Jr E. M., \& Silva O. H. M. (2013) Atividades experimentais: uma estratégia para o ensino da física. Cadernos Intersaberes, 1(2), 38-56.

Rosa, C. T. W., \& Rosa, A. B. (2004). A Teoria Histórico-Cultural e o Ensino da Física. Revista Iberoamericana de Educación, 33, nc.

Robilotta, M. R., \& Babichak, C. C. (1997). Definições e conceitos em Física. Ensino da Ciência, Leitura e Literatura. Cadernos Cedes, Campinas, 41(1), 35-45.

Schiff, M. (1994) A inteligência desperdiçada: desigualdade social, injustiça escolar. Tradução de W. Settineri. Porto Alegre: Artes Médicas Sul.

Vygotsky, L. S. (2004). Imagination \& creativity in childhood. Journal of Russian and East European Psychology, 42(1), 7-97.

Vygotsky, L. S. (1994). Imagination and creativity of the adolescent. In R. Van Der Veer, \& J. Valsiner, Ed. The Vygotsky reader. Oxford: Blackwell Publishers, 266-288.

Vygotsky, L. (1987). Pensamento e Linguagem. Tradução de Jefferson L. Camargo. São Paulo: Martins Fontes.

Wertsch, J. V. (1985). Vygotsky and the Social Formation of Mind. Cambridge: Harvard University Press.

Wertsch, J. V. (1993). Voices of the Mind: a sociocultural approach to mediated action. Cambridge: Harvard University Press. 


\section{Roberto Gonçalves Barbosa}

${ }^{(1)}$ http://orcid.org/0000-0002-0397-4754 Universidade Federal do Paraná - Setor Litoral Curitiba, Brasil betofisica@yahoo.com.br

\section{Irinéa de Lourdes Batista}

${ }^{\circ}$ https://orcid.org/0000-0001-8690-2344 Universidade Estadual de Londrina Londrina, Brasil irinea@uel.br

Submetido em 14 de Fevereiro de 2017 Aceito em 20 de Dezembro de 2017 Publicado em 08 de Março de 2018 